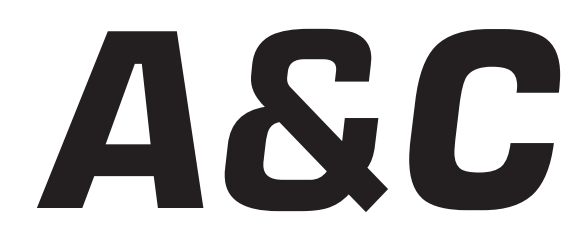

Revista de Direito Administrativo \& Constitucional

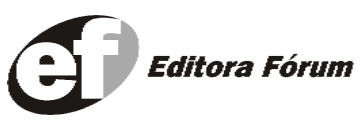

A\&C R. de Dir. Administrativo e Constitucional, Belo Horizonte, ano 5, n. 22, p. 1-253, out./dez. 2005 


\section{A\&C REVISTA DE DIREITO ADMINISTRATIVO E CONSTITUCIONAL}

\section{IPDA}

Instituto Paranaense

de Direito Administrativo

Direção Geral

Romeu Felipe Bacellar Filho

Direção Editorial

Paulo Roberto Ferreira Motta

Direção Executiva

Emerson Gabardo

Conselho de Redação

Edgar Chiuratto Guimarães

Adriana da Costa Ricardo Schier

Célio Heitor Guimarães

Conselho Editorial

Adilson Abreu Dallari

Alice Gonzáles Borges

Carlos Ari Sundfeld

Carlos Ayres Britto

Carlos Delpiazzo

Cármen Lúcia Antunes Rocha

Celso Antônio Bandeira de Mello

Clèmerson Merlin Clève

Clóvis Beznos

Enrique Silva Cimma

Eros Roberto Grau

Fabrício Motta

Guilhermo Andrés Muñoz (in memoriam)

Jaime Rodríguez-Arana Muñoz

Jorge Luís Salomoni
José Carlos Abraão
José Eduardo Martins Cardoso

José Luís Said

José Mario Serrate Paz

Juan Pablo Cajarville Peruffo

Juarez Freitas

Julio Rodolfo Comadira

Luís Enrique Chase Plate

Lúcia Valle Figueiredo

Manoel de Oliveira Franco Sobrinho

(in memoriam)

Marçal Justen Filho

Marcelo Figueiredo

Márcio Cammarosano

Maria Cristina Cesar de Oliveira
Nelson Figueiredo

Odilon Borges Junior

Pascual Caiella

Paulo Eduardo Garrido Modesto

Paulo Henrique Blasi

Paulo Neves de Carvalho (in memoriam)

Paulo Ricardo Schier

Pedro Paulo de Almeida Dutra

Regina Maria Macedo Nery Ferrari

Rogério Gesta Leal

Rolando Pantoja Bauzá

Sérgio Ferraz

Valmir Pontes Filho

Yara Stropa

Weida Zancaner

\footnotetext{
A246 A\&C Revista de Direito Administrativo e Constitucional. ano 3, n. 11, jan./mar. 2003. Belo Horizonte: Fórum, 2003.

Trimestral

ano 1, n.1, 1999 até ano 2, n.10, 2002 publicada pela Editora Juruá em Curitiba

ISSN: 1516-3210

1. Direito Administrativo. 2. Direito Constitucional. I. Fórum.
}

CDD: 342 CDU: 33.342

(c) Editora Fórum Ltda. 2005

Todos os direitos reservados. É proibida a reprodução total ou parcial, de qualquer forma ou por qualquer meio eletrônico ou mecânico, inclusive através de processos xerográficos, de fotocópias ou de gravação, sem permissão por escrito do possuidor dos direitos de cópias (Lei $n^{\circ}$ 9.610, de 19.02.1998).

Editora Fórum Ltda

Av. Afonso Pena, 2770 - 15\%16ªndar - Funcionários

CEP 30130-007 - Belo Horizonte/MG - Brasil

Tel.: 08007043737

Internet: www.editoraforum.com.br

e-mail: editoraforum@editoraforum.com.br
Editor responsável: Luís Cláudio Rodrigues Ferreira Projeto gráfico e diagramação: Luis Alberto Pimenta Revisora: Olga M. A. Sousa

Pesquisa jurídica: Fátima Ribeiro - OAB/MG 74868

Bibliotecária: Nilcéia Lage de Medeiros

CRB 1545/MG 6a região

Os conceitos e opiniões expressas nos trabalhos assinados são de responsabilidade exclusiva de seus autores.

Impressa no Brasil / Printed in Brazil

Distribuída em todo Território Nacional 


\title{
O Direito Fundamental à Saúde na Perspectiva da Constituição Federal ${ }^{1}$
}

\author{
Marcelene Carvalho da Silva Ramos \\ Procuradora do Estado do Paraná. Mestre em Direito do Estado (Direito Constitucional) pela \\ UFPF. Master em Teorías Críticas del Derecho y la Democracia en Iberoamérica pela Universidade \\ Internacional de Andalucía - Espanha. Professora de Direito Constitucional das Faculdades Inte- \\ gradas Curitiba e de Pós-Graduação do ISAE/FGV
}

Sumário: 1 Introdução: contextualizando o direito à saúde no âmbito da teorética contemporânea dos direitos fundamentais $\mathbf{- 2} \mathrm{O}$ direito fundamental à saúde como positivado na $\mathrm{CF} / 88$ - $3 \mathrm{Um}$ indispensável olhar sobre a jurisprudência acerca do direito à saúde $\mathbf{- 4}$ À guisa de conclusão

\section{Introdução: contextualizando o direito à saúde no âmbito da teorética contemporânea dos direitos fundamentais}

Como se sabe, a dogmática constitucional contemporânea classifica os direitos fundamentais em dois grandes grupos: os direitos fundamentais na condição de direitos de defesa e os direitos fundamentais como direitos a prestações - de natureza fática e jurídica. Os direitos fundamentais prestacionais, por sua vez, dividem-se em direitos a prestações em sentido amplo — direitos de proteção e direitos à participação na organização e procedimento - e os direitos a prestações em sentido estrito, ou direitos fundamentais sociais (direitos a prestações materiais sociais). ${ }^{2}$

Os direitos fundamentais de defesa são próprios do Estado Liberal de Direito e exigem uma abstenção estatal, ou seja, sua não-intervenção na esfera dos direitos de liberdade dos cidadãos; e os direitos fundamentais de ação ou a prestações exigem ações dos poderes públicos, consistentes em prestações fáticas ou jurídicas e são direitos próprios do Estado de Direito Democrático e Social. Nada obstante a divisão dos direitos fundamentais em direitos de defesa, de omissão estatal (liberdade abstrata) e os direitos fundamentais prestacionais, que impõem a atuação estatal, a fim de se assegurar a igualdade de condições ao livre desenvolvimento da

Conferência proferida no Seminário "O SUS e o Poder Judiciário no Paraná - Discutindo as políticas de Assistência Farmacêutica", realizado em 25-26 de novembro de 2004, pela Procuradoria Geral do Estado do Paraná e Secretaria de Estado da Saúde.

2 SARLET, Ingo W. A Eficácia dos Direitos Fundamentais. 2. ed. Porto Alegre: Liv. do Advogado, 2001, p. 170.

A \& C R. de Dir. Administrativo e Constitucional, Belo Horizonte, ano 5, n. 22, p. 147-165, out./dez. 2005 
personalidade humana (liberdade real), há uma nítida interpenetração dos direitos fundamentais. ${ }^{3}$

De outro vértice, os direitos fundamentais são a um só tempo direito objetivo e direito subjetivo, detendo, portanto, duplo caráter. São direitos subjetivos por que garantem um direito individual e impõem um dever estatal de assegurar tal direito. São direitos objetivos por que integram o ordenamento jurídico objetivo da coletividade. ${ }^{4}$

Os direitos prestacionais ou direitos a ações positivas do Estado compreendem as prestações em sentido amplo — os direitos à proteção e os direitos à organização e procedimento - e os direitos a prestação em sentido estrito ou propriamente os direitos fundamentais sociais.Aos direitos a prestações correspondem, portanto, posições jurídicas fundamentais distintas, conforme o seu objeto, podendo-se classificá-los em direitos a prestações jurídicas ou normativas e direitos a prestações fáticas ou materiais. Com isso, os direitos prestacionais não se restringem a prestações materiais, mas integram também direitos de proteção a posições jurídicas do cidadão em face do Estado, assim como direitos de participação na organização e procedimentos dos direitos fundamentais, sendo que estes se reportam ao Estado de Direito de matriz liberal na condição de garantes da liberdade e igualdade na sua dimensão defensiva.

Já a existência de direitos a prestações em sentido estrito dá-se no âmbito do Estado Social, são, aliás, direitos típicos do Welfare State e importam na sua atuação no sentido da criação, fornecimento e distribuição de prestações materiais, constituindo-se naqueles direitos fundamentais a prestações fáticas que o indivíduo, caso dispusesse dos recursos necessários e em existindo no mercado uma oferta suficiente, poderia obter também de particulares. ${ }^{5}$ São os denominados direitos fundamentais sociais

\footnotetext{
3 Nesse sentido, HESSE, Konrad. Elementos de Direito Constitucional. Porto Alegre: Sérgio Antonio Fabris, 1998, p. 235: "Como direitos do homem e do cidadão, os direitos fundamentais são, uma vez, direitos de defesa contra os poderes estatais. Eles tornam possível ao particular defender-se contra prejuízos não autorizados em seu status jurídico-constitucional pelos poderes estatais no caminho do direito. Em uma ordem liberal constitucional são necessários tais direitos de defesa, porque também a democracia é domínio de pessoas sobre pessoas, que está sujeito às tentações do abuso de poder, e porque poderes estatais, também no estado de direito, podem fazer injustiça".

4 HESSE, Konrad, op. cit., p. 228. "Por um lado eles são direitos subjetivos, direitos do particular, e precisamente, não só nos direitos do homem e do cidadão no sentido restrito.... mas também lá onde eles, simultaneamente, garantem um instituto jurídico ou a liberdade de um âmbito de vida.... Por outro, eles são elementos fundamentais da ordem objetiva da coletividade. Isso é reconhecido para garantias, que não contêm, em primeiro lugar, direitos individuais, ou, que em absoluto, garantem direitos individuais, não obstante estão, porém, incorporadas no catálogo de direitos fundamentais da Constituição."

5 Cfr. ALEXY, Robert. Teoria de Los Derechos Fundamentales. Madrid: Centro de Estúdios Constitucionales, 1997, p. 482 (tradução livre). Os direitos a prestações em sentido estrito são direitos do particular a obter
} 
e, assim como ocorre com os direitos de defesa e os direitos a prestações, há uma íntima interpenetração entre os direitos a prestações em sentido amplo e em sentido restrito, bem assim em torno de sua igual dignidade como direitos fundamentais. ${ }^{6}$

Os direitos fundamentais sociais são, também, em alguma medida, dependentes da organização e do procedimento para sua realização, bem como, podem ser considerados como parâmetro para a formatação das estruturas organizatórias e dos procedimentos, servindo, para além disso, como diretrizes para a aplicação e interpretação das normas procedimentais, servindo como garantias procedimentais. Em sentido estrito, os direitos à organização e ao procedimento asseguram ao indivíduo que o legislador dite normas de organização conformes ao direito fundamental (Alexy e Canotilho) e facilite procedimentos que possibilitem uma participação na formação da vontade estatal. Nesse contexto, para a garantia do acesso aos bens sociais é indispensável a preexistência de instituições, esquemas organizacionais e procedimentais que forneçam o suporte logístico, institucional e material assegurador da dinamização dos direitos sociais.

Para o juspublicista germânico Alexy, os direitos fundamentais são posições jurídicas tão importantes, que a outorga (ou não-outorga) não pode ficar livremente franqueada à disposição parlamentar. E, que, a questão acerca de quais são os direitos fundamentais sociais que o indivíduo possui definitivamente, resulta basicamente da ponderação entre princípios, de um lado o princípio da liberdade fática, de outro, os princípios formais de competência do legislador democraticamente legitimado e o princípio da divisão de poderes e ainda, princípios materiais que, sobretudo, refiram-se à liberdade jurídica de outros e também a outros direitos fundamentais sociais e a bens coletivos. ${ }^{7}$

\footnotetext{
através do Estado bens sociais (saúde, educação, segurança social), que não os pode obter no comércio privado, seja pela escassez dos seus recursos financeiros, seja por resposta insatisfatória do mercado (cuidados de saúde privados, seguros privados, ensino privado). São direitos sociais, indistintamente, todos aqueles que dependem da providência estatal, ou seja, da ação positiva do Estado, a quem cabe assegurar prestações existenciais dos cidadãos.

6 Cfr. SARLET, Ingo. A Eficácia..., p. 195

7 ALEXY, Robert. Teoria de los Derechos Fundamentales, p. 494. Diversamente do que ocorre no ordenamento jurídico-constitucional brasileiro, a Lei Fundamental de Bonn - ao contrário também das Constituições dos Estados-federados alemães — é cautelosa na formulação dos direitos a prestações, só explicitando um direito fundamental social no sentido de direito subjetivo à prestação para o direito da mãe à proteção e assistência por parte da comunidade (art. 6, §4․, LF), por isso, eles têm que ser deduzidos de outras disposições jusfundamentais. Isso porque, tanto do ponto de vista de seu texto como de sua gênese, a Lei Fundamental alemã tem primariamente o caráter de uma Constituição burguesa e de Estado de Direito voltada para os direitos de defesa. Alexy alerta que ocorre colisão entre direitos fundamentais sociais de uns e os direitos de liberdade de outros também devido aos custos financeiros decorrentes do cumprimento dos direitos fundamentais sociais, já que o Estado só pode distribuir aquilo que consegue arrecadar com os tributos sem lesionar os direitos fundamentais dos contribuintes e que, as colisões entre direitos fundamentais sociais e bens coletivos resultaria da absorção de grande parte do orçamento público para a realização de ambos, em face dos seus efeitos financeiros (p. 493-494).
} 
Como resultado dessa ponderação entre princípios, deverão estar presentes condições que assegurem e satisfaçam direitos fundamentais sociais mínimos, ou seja, direito a um mínimo vital, que garantam um padrão mínimo de saúde, educação, moradia, trabalho, lazer, segurança, previdência social, que renda homenagem ao princípio da dignidade humana. Assim, uma tal compreensão de direito subjetivo vinculante prima facie (ou seja, de princípio) dos direitos sociais fundamentais, significa que, para além do caráter programático das normas que vinculam esses direitos, a sua cláusula restritiva, qual seja, a reserva do possível - aquilo que o indivíduo pode razoavelmente exigir da sociedade - não pode ter como conseqüência a ineficácia desse direito e sim, deve-se compreender que tal cláusula expressa a necessidade de ponderação desse direito. ${ }^{8}$

Já no direito português, pode-se afirmar, ${ }^{9}$ com base nos acórdãos $\mathrm{n}^{\mathrm{o}} 39 / 84$ e $\mathrm{n}^{\circ} 101 / 92$ proferidos pelo Tribunal Constitucional, que os direitos sociais são compreendidos como autênticos direitos subjetivos inerentes ao espaço existencial do cidadão, independentemente da sua justicialidade e exeqüibilidade imediatas. Assim, o direito à segurança social, o direito à saúde são direitos com a mesma dignidade subjetiva dos direitos, liberdades e garantias, e portanto nem o Estado nem terceiros podem agredir posições jurídicas incrustadas no âmbito de proteção destes direitos.

No desenvolvimento da compreensão dos direitos sociais no Brasil, destaca-se, primeiramente, que a doutrina aponta para o duplo caráter dos direitos fundamentais, concebendo-os a um só tempo como direitos subjetivos - aptos a outorgar aos seus titulares a possibilidade de impor os seus interesses em face dos órgãos públicos — e como direitos objetivos - enquanto elementos fundamentais da ordem constitucional objetiva, formadores da base do ordenamento jurídico do Estado de Direito democrático. ${ }^{10}$

\footnotetext{
8 Cfr. ALEXY, Robert. Teoria..., p. 499.

${ }^{9}$ CANOTILHO, J.J. Gomes. Direito Constitucional e Teoria da Constituição. 2. ed. Coimbra: Almedina, 1998, p. 434. Com fundamento ainda no Acórdão $n^{\circ} 39 / 84$, do Tribunal Constitucional, referente à extinção legal do Serviço Nacional de Saúde de Portugal, Canotilho ressalta que assim se revela a força jurídicoconstitucional dos direitos sociais: (i) os direitos fundamentais sociais consagrados constitucionalmente dispõem de vinculatividade normativo-constitucional, não são, portanto, meros "programas" ou linhas de direção política"; (ii) as normas garantidoras de direitos sociais devem servir de parâmetro de controlo judicial quando estejam em causa a apreciação da constitucionalidade de medidas legais ou regulamentares restritivas destes direitos; (iii) as normas de legislar acopladas à consagração de direitos sociais são autênticas imposições legiferantes, cujo não cumprimento poderá justificar a inconstitucionalidade por omissão; (iv) as tarefas constitucionalmente impostas ao Estado para a concretização destes direitos devem traduzir-se na edição de medidas concretas e determinadas e não em promessas vagas e abstratas; (v) a produção de medidas concretizadoras dos direitos sociais não está à livre disponibilidade do legislador, inobstante sua liberdade de conformação, quer quanto às soluções normativas concretas, quer quanto ao modo de organização e ritmo de concretização.

10 Por todos: SARLET, Ingo W. A Eficácia dos Direitos Fundamentais.
} 
Considera-se, ainda, que os direitos de defesa são insuficientes para assegurar a liberdade real, que depende de ações positivas do Estado, de intervenção e não de abstenção, pois cuida-se não-só de ter liberdade em relação ao Estado, mas de desfrutar dessa liberdade por meio das prestações advindas do Estado. Cuida, assim, a moderna dogmática dos direitos fundamentais sociais, da possibilidade de o Estado obrigar-se à criação dos pressupostos fáticos necessários ao exercício efetivo dos direitos constitucionalmente assegurados e sobre a possibilidade do titular do direito impor sua pretensão a prestações em face do Estado.

É, pois, ponto nuclear da teoria dos direitos fundamentais do Estado Social - que pretende superar o choque entre liberdade jurídica e liberdade real - que os direitos fundamentais não têm só um caráter delimitador negativo, mas também, o caráter de facilitador de prestações sociais pelo Estado, cabendo a este buscar os meios de criar os pressupostos sociais necessários para a realização desses direitos fundamentais e favorecêlos. Também, os direitos fundamentais sociais visam assegurar, mediante prestações materiais a compensação das desigualdades sociais, proporcionando o exercício de liberdade e igualdade reais e efetivas, o que pressupõe um comportamento ativo do Estado, já que a igualdade material não se oferece simplesmente por si mesma, devendo ser devidamente implementada. ${ }^{11}$

\section{0 direito fundamental à saúde como positivado na $\mathrm{CF} / 88$}

Vimos que a doutrina nacional reconhece o caráter complementar entre os direitos de defesa e os direitos sociais a prestações materiais, rechaçando qualquer dualidade ou dicotomia entre eles, além de atribuir a mesma dignidade a ambas as categorias (ou dimensões) dos direitos fundamentais. Entretanto, reafirma suas distinções, que se revelam para além de seu objeto — abstenção ou ação estatal — na esfera da densidade normativa e da eficácia das normas que os consagram e que deságuam, principalmente, no problema central do reconhecimento de um direito individual subjetivo a prestações materiais.

Vem da doutrina lusitana a compreensão de que os direitos fundamentais a prestações podem ser concebidos como direitos originais e direitos derivados a prestações. Aqueles são definidos como posições jurídicas que podem ser deduzidos diretamente das normas constitucionais que consagram direitos sociais, independentemente da atuação legislativa. Estes

"SARLET, Ingo W. A Eficácia..., p. 202.

A \& C R. de Dir. Administrativo e Constitucional, Belo Horizonte, ano 5, n. 22, p. 147-165, out./dez. 2005 
dependem da prévia existência de um sistema de prestações estatais, e se caracterizam como direitos de igual acesso a elas. É que, as normas constitucionais que veiculam direitos fundamentais podem ser de eficácia plena e aplicabilidade imediatas ou de eficácia limitada e aplicabilidade mediata, dependentes, estas, de integração legislativa.

Por outro lado, o conteúdo da prestação não pode ser estabelecido e definido de forma geral e abstrata, dada a especificidade de cada direito fundamental prestacional. Saliente-se, também que cada direito social à prestação apresenta um vínculo diferenciado em relação às categorias de prestações estatais referidas (direito ao trabalho, assistência social, aposentadoria, educação, saúde, moradia, etc.). É a forma de positivação no texto constitucional das diferentes espécies de prestações que efetivamente irão constituir o objeto dos direitos sociais, bem como a sua concretização pelo legislador.

Assim, somente em alguns casos é que os direitos sociais conferem aos cidadãos um direito imediato a uma prestação efetiva, sendo necessário que tal decorra expressamente do texto constitucional. É o que sucede designadamente no caso do direito à saúde, que deve ser realizado, por meio de um serviço nacional de saúde, de acesso universal, e gratuito, nos termos preconizados constitucionalmente.

Com relação à eficácia ${ }^{12}$ das normas constitucionais veiculadoras do direito fundamental à saúde, vê-se já no Preâmbulo da Constituição Federal, e ainda no art. $3^{\circ}$, inc. III, que os direitos sociais prestacionais encontram-se intimamente vinculados às funções do Estado na sua expressão enquanto Estado Democrático Social, que deve zelar por uma adequada e justa distribuição e redistribuição dos bens existentes, a fim de reduzir as desigualdades sociais.

Sendo assim, é extreme de dúvidas que a Lei Maior brasileira ${ }^{13}$ positivou o direito à saúde como direito fundamental social, incluindo-o no

\footnotetext{
12 Reafirme-se, ainda, quanto à eficácia do direito fundamental à saúde, a regra principiológica de maximização da eficácia e de vinculação aos poderes públicos (e também no âmbito das relações privadas) contida no art. $5^{\circ}, \S 1^{\circ}, \mathrm{CF}$.

13 SCHWARTZ, Germano. Direito à Saúde: Efetivação em uma Perspectiva Sistêmica. Porto Alegre: Liv. do Advogado, 2001, p. 43-48. A Constituição Imperial de 1824 assim como a Republicana de 1891 nada dispuseram acerca do direito à saúde. Somente com a Constituição de 1934, e o surgimento de um suposto Estado Social brasileiro, o tema foi tratado e apenas do ponto de vista da competência concorrente da União e dos Estados para legislar sobre o tema (art. 10, II). As Constituições de 1937 e 1946 novamente silenciaram sobre o direito à saúde. No plano internacional, Constituição Italiana de 1948 foi pioneira, adotando a orientação da OMS (Organização Mundial da Saúde), que passou a adotar a concepção de saúde como bem-estar físico e mental e não só como ausência de doença, como ocorria com a concepção
} 
Catálogo dos Direitos Fundamentais, no artigo 6 ${ }^{\circ}$, Título II - Dos Direitos e Garantias Fundamentais, Capítulo II - Dos Direitos Sociais. Assim é que o constituinte de 1988 inscreveu: "Art. $6^{\circ}$. São direitos sociais a educação, a saúde, o trabalho, a moradia, o lazer, a segurança, a previdência social, a proteção à maternidade e à infância, a assistência aos desamparados, na forma desta Constituição." 14

Insculpiu, ainda, o legislador constituinte, agora fora do Catálogo: "Art. 196. A saúde é direito de todos e dever do Estado, garantido mediante políticas sociais e econômicas que visem à redução do risco de doença e de outros agravos e ao acesso universal igualitário às ações e serviços para sua promoção, proteção e recuperação."

Oportuno destacar, que o direito à saúde tem duas faces: uma, a da preservação da saúde, outra, a da proteção e recuperação da saúde. $\mathrm{O}$ direito à preservação da saúde tem como contrapartida as políticas que visam à redução do risco de doença, situando-se o próprio direito a um meio ambiente sadio. Está aqui uma prevenção genérica, não individualizável, da doença. O direito à proteção e recuperação da saúde é o direito individual à prevenção da doença e seu tratamento traduz-se no acesso aos serviços e ações destinados à recuperação do doente. Enquanto o primeiro é típico direito de solidariedade, o segundo é típico direito fundamental à prestação positiva.

A saúde é, ainda, direito individual, coletivo, metaindividual (transindividual e difuso). ${ }^{15}$

\footnotetext{
do Estado Liberal (que tinha como objetivo tratar da doença para repor o trabalhador em seu posto de trabalho, visando o acúmulo de capital). A Declaração Universal dos Direitos do Homem, de 1948, elencou, em seu artigo 25, a saúde como elemento da cidadania. A partir daí, as Constituições contemporâneas recepcionaram o tema, com destaque para a Constituição Portuguesa de 1976 e o Direito alemão. Contudo, a Constituição Brasileira de 1967, em seu art. 8 XIV, apenas delegava à União a competência de estabelecer planos nacionais de educação e saúde, sem avanços mais significativos no que respeita à proteção da saúde. Somente com a Constituição de 1988 o direito à saúde foi positivado como direito fundamental social.

14 Para a doutrina, o atributo social do direito determina, de maneira objetiva, a obrigação ao Estado de assegurar aos indivíduos um conjunto de regras de proteção e atendimento que possibilite a plena realização da condição humana. E que, o constituinte, adotando uma visão moderna da função do Estado, procurou assegurar direitos básicos inerentes à dignidade humana, com o que, os indivíduos passaram a ser titulares de uma espécie de crédito junto ao Estado, que lhes é devedor de determinadas prestações sociais.

15 De acordo com a Teoria da Geração de Direitos Humanos de Norberto Bobbio (A Era dos Direitos. 9. ed. Rio de Janeiro: Campos, 1992, p. 217, o direito à saúde é direito de $1^{a}, 2^{a}, 3^{a}$, $4^{a}$, e $5^{a}$ gerações. Assim, como direito de $1^{\text {a }}$ Geração protege a vida prevalecendo a autonomia da vontade; como direito de $2^{a}$ Geração, tipifica o direito à saúde como direito social; como direito de $3^{a}$ Geração, o direito à saúde constitui direito coletivo e difusos (transindividual); como direito de $4^{a}$ Geração, o direito à saúde remete aos direitos de bioética, biotecnologia e bioengenharia; e finalmente, como direito de $5^{a}$ Geração, o direito à saúde está abrangido pelos direitos de realidade virtual, revolução cibernética e internet. (Cfr. também SCHWARTZ, Germano. Direito à... p. 52-56.)
} 
Ainda acerca da positivação do direito à saúde na Carta Democrática brasileira, é de se ressaltar o que dispõe o art. 197: "Art. 197. São de relevância pública as ações e serviços de saúde, cabendo ao Poder Público dispor, nos termos da lei, sobre sua regulamentação, fiscalização e controle, devendo sua execução ser feita diretamente ou através de terceiros e, também, por pessoa física ou jurídica de direito privado." Assim, o atendimento à saúde reclama serviços e ações de prevenção, tratamento e recuperação, em termos individualizados, o que requer a intervenção legislativa que os regulamente, fiscalize e controle. Tal como ocorreu com a edição da Lei Orgânica da Saúde (Lei no 8.080/90).

Prevê, ainda, o art. 198/CF: "Art. 198. As ações e serviços públicos de saúde integram uma rede regionalizada e hierarquizada e constituem um sistema único, organizado de acordo com as seguintes diretrizes:...". Os serviços e ações de saúde pública dão-se por um Sistema Único de Saúde - SUS, mantido pelo Poder Público. Os incisos e parágrafos do artigo 198 tratam da descentralização dos serviços de saúde, do atendimento integral, da participação da comunidade nos serviços e ações voltadas ao atendimento da saúde e do seu financiamento (cfr. art. 195).

O artigo 199 e seus parágrafos dispõem acerca da liberdade conferida à iniciativa privada para, de forma complementar, participar do sistema único de saúde, por meio de contrato de direito público ou convênio, seguindo as diretrizes do SUS, proibindo a ela auxílios e subvenções, como também, vedando a participação direta ou indireta de empresas ou capitais estrangeiros na assistência à saúde, salvo expressa disposição legal. O artigo 200, caput, estabelece a competência e atribuições do SUS - Sistema Único de Saúde, remetendo a sua disciplina à lei, nos termos dos artigos 23, II e 24, XII, todos da Constituição Federal. ${ }^{16}$

Como bem observa Ingo Sarlet, é nos arts. 196 e ss. que o direito à saúde encontrou sua maior concretização ao nível normativo-constitucional. ${ }^{17}$ Entretanto, como ocorre com os demais direitos sociais prestacionais, o direito à saúde tem sido considerado, no nosso ordenamento jurídico, como dependente de intermediação legislativa, negando-se-lhe a natureza de norma de eficácia plena. Remanesce, assim a questão da exigibilidade

\footnotetext{
${ }^{16}$ Eis o arcabouço normativo-constitucional da proteção jurídica do direito à saúde no ordenamento jurídico brasileiro, com destaque ainda para o art. $5^{\circ}, \S 1^{\circ}$, já referido e a regra inserida pela Emenda Constitucional $n^{\circ} 41 / 03$, que preceitua: "Art 5- (...) $3^{\circ}$ - Os tratados e convenções internacionais sobre direitos humanos que forem aprovados, em cada Casa do Congresso Nacional, em dois turnos, por três quintos dos votos dos respectivos membros, serão equivalentes às emendas constitucionais."

17 SARLET, Ingo W., op. cit., p. 301.
}

A \& C R. de Dir. Administrativo e Constitucional, Belo Horizonte, ano 5, n. 22, p. 147-165, out./dez. 2005 
perante o Estado de tais prestações materiais, isto é, se vinculam juridicamente os poderes públicos — e portanto, se são ou não sindicáveis judicialmente.

Especificamente no que respeita ao direito à saúde, constitui exigência de um Estado democrático, que inclui valores essenciais como a dignidade humana, o reconhecimento de um direito originário a prestações, no sentido de um direito subjetivo individual a prestações materiais, ainda que no nível de um mínimo vital, para a proteção da vida humana, diretamente deduzido da Constituição.

Reconhece-se, por outro lado, que mesmo tendo o cidadão um direito a prestações existenciais mínimas, decorrentes do direito à vida, não se pode impor ao poder público o modo de realizar este direito, porquanto os órgãos estatais dispõem de um indispensável espaço de discricionariedade, que, no entanto, não é absoluto, condicionado que está à realização do núcleo essencial do direito fundamental positivado.

Contudo, assegurar ao indivíduo, mediante a prestação de recursos materiais essenciais, uma existência digna é objetivo comum dos direitos fundamentais sociais, daí a íntima vinculação entre os direitos à saúde e o direito à vida, e ainda, o princípio da dignidade da pessoa humana, sendo que, este constitui fundamento da República Federativa do Brasil (art. $1^{\circ}$, inc. III, CF) e, bem assim, fim da ordem econômica (art. 170, caput).

Entretanto, as normas consagradoras de direitos sociais ainda são, para grande parte da doutrina, normas programáticas, que veiculam programas constitucionais de atuação dos poderes públicos dependentes de providências integrativas. Todavia, toda norma constitucional é dotada de eficácia jurídica e deve ser interpretada e aplicada em busca de sua máxima eficácia. Todas as normas constitucionais são dotadas de um mínimo de eficácia (eficácia negativa, derrogatória), variável de acordo com seu grau de densidade normativa e, nessa medida, direta e imediatamente aplicáveis. É nesse ponto que releva destacar que a Carta Federal de 1988, de forma inovadora, dispôs em seu art. $5^{\circ}, \S 1^{\circ}$, que "as normas definidoras dos direitos e garantias fundamentais têm aplicação imediata".

Dessa forma, a aplicabilidade imediata das normas de direito fundamental, desloca a doutrina dos "direitos fundamentais dentro da reserva de lei" para a doutrina da reserva de lei dentro dos direitos fundamentais". Contrapõe-se à doutrina que defende a dependência legal (por meio da interpositio legislatoris) dos direitos fundamentais que 
pressupõem prestações do Estado, concebendo-os como leges imperfectae, posicionando-os como problema de competência constitucional, atribuindo ao legislador, respeitadas as condições orçamentárias, garantir as prestações sociais.

Como vimos acima, é notadamente a forma de positivação dos direitos fundamentais sociais no texto constitucional que confere a tais normas sua densidade normativa, sendo que, de acordo com as técnicas de positivação decorrem posições jurídicas distintas. Com isso, a sua carga eficacial está diretamente vinculada a sua positivação jurídicoconstitucional, dentre as possibilidades de conformação jurídica dos direitos sociais: como normas programáticas, como normas de organização, como garantia institucional e como direitos subjetivos públicos.

Diante do princípio da aplicabilidade imediata inscrito no artigo $5^{\circ}$, $\S 1^{\circ}$ da Constituição Federal, poder-se-ia advogar a tese da eficácia plena de todas as normas de direitos fundamentais, inclusive os direitos sociais, como o fazem os que propugnam a inexistência em nossa Constituição de normas programáticas. Entretanto, isso equivaleria a tornar dispensáveis - e até mesmo inaplicáveis à espécie os institutos de cunho jurídico-processual (mandado de injunção e ação direta de inconstitucionalidade por omissão). ${ }^{18}$

Diante disso, é plausível concluir que o art. $5^{\circ}, \S 1^{\circ}, \mathrm{CF}$, contém um postulado de otimização das normas consagradoras dos direitos fundamentais, inclusive, dos direitos sociais - neles compreendido o direito fundamental à saúde - impondo aos Poderes Públicos a tarefa de maximizar a eficácia dos direitos fundamentais, vinculando-os. Assim, a vinculatividade normativo-constitucional dos direitos fundamentais sociais impõe aos poderes públicos a realização destes direitos através de medidas políticas, legislativas e administrativas concretas e determinadas. ${ }^{19}$

No Brasil, na ausência de norma expressa, pode-se asseverar que a vinculatividade da Administração Pública aos direitos fundamentais, inclusive sociais, decorre da própria regra que determina sua aplicação imediata $\left(\operatorname{art.} 5^{\circ}, \S 1^{\circ}\right)$, assumindo a função de reforçar o caráter vinculante das normas de direitos fundamentais (reforço da eficácia vinculante), que ressalta o dever específico dos poderes públicos de respeitar e promover os direitos fundamentais, tomando-as como parâmetro na concretização de tais direitos.

No que concerne ao âmbito da vinculação do legislador aos direitos

\footnotetext{
18 SARLET, Ingo W. A Eficácia..., p. 244.

${ }^{19}$ CANOTILHO, J.J. Gomes. Direito Constitucional..., p. 471. A vinculação do legislador, juizes e administração aos direitos fundamentais, no direito português decorre diretamente de regra constitucional (art. 18/1, CP).
} 
fundamentais, especialmente no que respeita aos direitos sociais - com destaque para o direito fundamental à saúde - há que atentar para a imposição constitucional a ele dirigida, de concretização de tais direitos, sob pena de incorrer em inconstitucionalidade por omissão decorrente da inércia (total ou parcial).

Destarte, o Poder Executivo e todos os órgãos da Administração Pública encontram-se vinculados aos direitos sociais, em decorrência do princípio da máxima eficácia plasmado no art. $5^{\circ} \S 1^{\circ}$ o que significa que os órgãos administrativos devem executar apenas as leis que àqueles sejam conformes, bem como executar estas leis de forma constitucional, isto é, aplicando-as e interpretando-as em conformidade com os direitos fundamentais. ${ }^{20}$

Alerta, ainda, Ingo Sarlet, que os Tribunais, enquanto órgãos do Estado, estão submetidos à Constituição, devendo respeitar os direitos fundamentais, quer no processo, quer no conteúdo de suas decisões, assumindo especial relevância a função do controle de constitucionalidade dos atos dos órgãos estatais, o que lhes confere o poder/dever de não aplicar os atos contrários à Constituição, de modo especial os ofensivos aos direitos fundamentais, inclusive declarando-lhes a inconstitucionalidade. Bem assim, é dever dos tribunais interpretar e aplicar as leis em conformidade com os direitos fundamentais e ainda de colmatar eventuais lacunas à luz das normas de direitos fundamentais. ${ }^{21}$

Todavia, ante o fato de os direitos fundamentais sociais (v.g. o direito à saúde) exigirem prestações do Estado diretamente vinculadas à destinação, distribuição e redistribuição, bem como à criação de bens materiais, põe-se em relevo sua dimensão econômica. O caráter prestacional dos direitos sociais assume especial relevância no âmbito de sua eficácia e efetivação, significando que a efetiva realização das prestações reclamadas não é possível sem que se despenda algum recurso, dependendo, em última análise, da conjuntura econômica. ${ }^{22}$

Assim, diante da questão econômica que envolve os direitos sociais, a doutrina e a jurisprudência alemãs condicionaram a efetivação dos direitos fundamentais sociais à "reserva do financeiramente possível", tendo consignado a Corte Constitucional daquele país, no julgamento acerca de vagas nas universidades, que pretensões destinadas a criar os pressupostos

\footnotetext{
20 SARLET, Ingo W. A Eficácia... p. 331.

${ }^{21}$ Cfr. SARLET, Ingo. A Eficácia... p. 335.

22 Cfr. SARLET, Ingo W. A Eficácia... p. 263-264.
}

A \& C R. de Dir. Administrativo e Constitucional, Belo Horizonte, ano 5, n. 22, p. 147-165, out./dez. 2005 
necessários para o exercício de determinado direito estão submetidos à reserva do possível. ${ }^{23}$

Com efeito, a cláusula restritiva da reserva do possível constitui limite fático e jurídico à efetivação dos direitos sociais, apresentando-se sob duas faces: por um lado o Estado possui uma capacidade limitada de recursos materiais disponíveis, e por outro lado, deve ter a capacidade jurídica de dispor dos recursos existentes.

Para além da existência dos meios materiais efetivos e do poder de sua disposição, a pretensão deve ser razoável, e o que constitui o razoável numa pretensão que reclama prestação material, está diretamente relacionado à afetação material dos recursos, o que requer uma opção, que em derradeira análise cabe ao legislador e ainda ao administrador, por meio da opção de políticas públicas.

Entretanto, deixar à competência do legislador ordinário a opção quanto à escolha e direcionamento da destinação dos recursos materiais no que respeita aos direitos sociais, pode-se incorrer no risco de sua nãoconcretização pela escassez dos recursos. De outra face, outorgá-la ao Poder Executivo, concedendo-lhe o poder amplamente discricionário de deixar de concretizar o direito social alegando impedimento de ordem financeira, não se afigura adequado. Ao Judiciário, todavia, a doutrina mostra reservas quanto a conferir-lhe o poder de remanejar verbas públicas.

Vê-se, pois, que os argumentos que refletem a preocupação com a questão orçamentária como restrição à efetivação dos direitos sociais fundamentais, como o direito à saúde, choca-se com a garantia constitucional de proteção à vida e à dignidade humana. Assim, por mais que os poderes públicos, como destinatários precípuos de um direito à saúde, venham a opor os habituais argumentos da ausência de recursos e da incompetência dos órgãos judiciários para decidirem sobre a alocação e destinação de recursos públicos há que se ter presente que está em jogo a preservação do bem maior da vida humana.

Oportuno se afigura trazer à discussão o princípio da proibição de retrocesso $o^{24}$ visa impedir o legislador de abolir determinadas posições jurídicas por ele próprio criadas. A proibição do retrocesso social é princípio

\footnotetext{
${ }^{23}$ MENDES, Gilmar Ferreira, op. cit., p. 43-44.

${ }^{24}$ Acerca da proibição de retrocesso ver SARLET, Ingo W. A Eficácia..., p. 275. Por todos: CANOTILHO. Direito Constitucional.... p. 320-321, para quem, a proibição de retrocesso social decorre do princípio da democracia econômica e social, significando que, os direitos sociais e econômicos, uma vez obtido um determinado grau de realização, passam a constituir, simultaneamente, uma garantia institucional e um direito subjectivo.
} 
constitucional que decorre da democracia e do Estado Social e significa que, os direitos sociais, uma vez obtido um determinado grau de realização, passam a constituir uma garantia institucional não podendo ser eliminados ou reduzidos a ponto de atingir o núcleo essencial do direito consagrado constitucionalmente. A liberdade de conformação do legislador encontra seu limite no núcleo essencial já realizado, transformando o direito social, nessa medida, em direito de defesa, impondo ao Estado que se abstenha de atentar contra ele.

É cabível concluir que, independentemente da questão orçamentária, os direitos sociais constituem direitos fundamentais subjetivos vinculantes, oponíveis ao Estado e plenamente jurisdicizados, sendo que para além de assegurarem o minimo vital representam a derradeira garantia da dignidade humana, em ordenamentos jurídicos que consagram um Estado de Direito Democrático, como o brasileiro.

\footnotetext{
${ }^{25}$ Consistentes na exigência de preenchimento de requisitos impostos pela legislação que criou o SUS Serviço Único de Saúde (Lei Orgânica da Saúde - Lei n 8.080, de 19.09.90) e por decretos e regulamentos que orientam o procedimento e atendimento ao serviço de saúde pública, evidenciando a exigência da intermediação legiferante e conseqüente observação das prescrições legais e normas infra-legais.

${ }^{26}$ No mesmo sentido, os seguintes julgados: TJ/PR, MS n. 070.086.100, Des. Rel. Ivan Bortoleto, DJ, 5 ago. 1999. No mesmo sentido: TJ/PR MS n. 067.579.600, MS n0 074.853.800, MS nº 069.321.800.

${ }^{27}$ Essa decisão foi reformada pelo STJ, no RMS n $11.129 / \mathrm{PR}$.
} 
28 STJ, RMS no 11.129/PR, Min Rel. Francisco Peçanha Martins, DJ, 18 fev. 2002.

${ }^{29} \mathrm{Na}$ mesma direção, as seguintes decisões: TJ/PR, MS n 137.626.300, Des. Rel. Luiz Cezar de Oliveira, DJ,

15 maio /2003. No mesmo sentido: TJ/PR MS no 127.201.300, MS n 146.245.700, MS nº 149.645.900,

STJ RESP 430.526, RESP 325.337.

A \& C R. de Dir. Administrativo e Constitucional, Belo Horizonte, ano 5, n. 22, p. 147-165, out./dez. 2005 


\footnotetext{
30 "ADMINISTRATIVO. RETINOSE PIGMENTAR. TRATAMENTO MÉDICO EM CUBA. EFICÁCIA. NECESSIDADE DE COMPROVAÇÃO. DILAÇÃO PROBATÓRIA. AUSÊNCIA DE PROVA CABAL DO DIAGNOSTICO DA PATOLOGIA E EFICÁCIA DO TRATAMENTO EM CUBA 1. O rito especialíssimo do mandado de segurança não comporta a realização de perícia técnica apta a comprovar o diagnóstico da patologia e a eficácia do tratamento realizado em Cuba. 2. Produção comprobatória que se justifica em face de manifestação do Conselho Brasileiro de Oftalmologia e do Presidente da Fundação Brasileira de Reabilitação Visual asseverando a inexistência, na literatura médica, de comprovação científica que abone a terapia adotada em Cuba para combater a retinose pigmentar, bem como, a possibilidade do tratamento almejado ser realizado aqui no Brasil. 3. Definidas pela Administração as metas prioritárias na área de saúde pública, dentro do âmbito da discricionariedade de que dispõe e sem ofensa aos limites legais e constitucionais, não cabe ao Judiciário perquirir os critérios adotados, tampouco substituí-los. Daí porque, na espécie, não padece de ilegalidade a Portaria $n^{\circ}$ 763, de 07.04.1994, editada pelo Ministério da Saúde, que proibiu o custeio de tratamento médico no exterior por conta do Estado.4. Apelação e remessa oficial providas" (TRF $1^{a}$ Região, MS n ${ }^{\circ}$ 8.895/DF. DJ, 22 out. 2003).

${ }^{31}$ Decisão confirmada pela Corte Especial do STJ, nos autos de STA n. 81, conforme noticiado no site $<$ http://www.stj.gov.br/webstj/Noticias/detalhes noticias.asp? seq_noticia $=14473>$.

${ }^{32}$ Confira-se ainda a seguinte decisão: STJ, RESP 616.460/DF, Min. Rel. Teori Albino Zavascki, DJ de 21.03.2005. "(...) Entretanto, que elementos temos no mandado de segurança para duvidar do ato da autoridade que diz que o tratamento pretendido não é recomendável cientificamente? Que autoridade, nós, juízes, temos para duvidar disso? Não vejo como não considerar legítima a opção do administrador,
}

A \& C R. de Dir. Administrativo e Constitucional, Belo Horizonte, ano 5, n. 22, p. 147-165, out./dez. 2005 
ainda mais fundada no parecer. Ponhamo-nos no papel de quem tem o dever técnico de administrar a escassez de recursos num País pobre como o nosso, e de fazer as opções políticas para dar-lhes destinação. Portanto, não há como ter presente, no caso, direito líquido e certo a obter do Estado a liberação de vultuosa quantia necessária ao atendimento individual da impetrante. Não há dúvida de que a saúde é um direito fundamental, mas, também é certo, não se trata de direito absoluto. (...)"

A \& C R. de Dir. Administrativo e Constitucional, Belo Horizonte, ano 5, n. 22, p. 147-165, out./dez. 2005 
A \& C R. de Dir. Administrativo e Constitucional, Belo Horizonte, ano 5, n. 22, p. 147-165, out./dez. 2005 
A \& C R. de Dir. Administrativo e Constitucional, Belo Horizonte, ano 5, n. 22, p. 147-165, out./dez. 2005 
\lceil

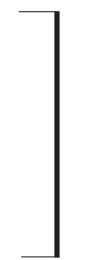

A \& C R. de Dir. Administrativo e Constitucional, Belo Horizonte, ano 5, n. 22, p. 147-165, out./dez. 2005 